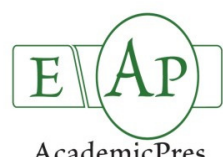

AcademicPres

\title{
Effects of Arbuscular Mycorrhiza Fungi on Growth Characteristics of Dactylis glomerata L. under Drought Stress Conditions
}

\author{
Apostolos P. KYRIAZOPOULOS ${ }^{1 *}$, Michail ORFANOUDAKIS ${ }^{1}$, Eleni M. \\ ABRAHAM ${ }^{2}$, Zoi M. PARISSI ${ }^{2}$, Nikoleta SERAFIDOU ${ }^{1}$ \\ ${ }^{1}$ Democritus University of Thrace, Department of Forestry and Management of the Environment and Natural Resources, 193 Pantazidou str., \\ 68200 Orestiada, Greece; apkyriaz@fmenr.duth.gr (*corresponding author) \\ ${ }^{2}$ Aristotle University of Thessaloniki, Department of Forestry and Natural Environment, Laboratory of Range Science (236), 54124 \\ Thessaloniki, Greece
}

\begin{abstract}
Limited information is available regarding the selection of effective mycorrhizae and the exploitation of their beneficial effects on the enhancement of the forage production of Dactylis glomerata under the predicted warmer and drier conditions in the Mediterranean region. The objective of this study was to test the effects of Glomus intraradices, Glomus mosseae and their mix inoculation on growth characteristics and dry matter production of Dactylis glomerata in relation to full and limited irrigation. The experiment was conducted in Orestiada, Northeastern Greece. Limited irrigation significantly decreased yield and yield components of Dactylis glomerata over the full irrigation. Drought stressed plants had significantly higher root dry weight as a response for better survival under water deficit conditions. The Arbuscular mycorrhizal fungi (AMF) inoculated plants had significant higher shoot dry weight, tiller height and number of leaves in comparison to the non-inoculated plants. On the contrary, under drought stress conditions all AMF plants had lower root dry weights than control plants. Among the studied mycorrhizae species, Glomus intraradices performed better than Glomus mosseae and their mixture as it increased S/R ratio, tiller height and number of leaves.
\end{abstract}

Keywords: forage, Glomus intraradices, Glomusmosseae, Mediterranean region, orchardgrass

\section{Introduction}

Water availability is one of the most ominous abiotic factors limiting the productivity of forage crops in the Mediterranean region. It is predicted that due to climatic change, precipitation will significantly reduce in the Mediterranean region (Bates et al., 2008). The predicted warmer and drier climate conditions will considerably affect the grassland ecosystems' goods and services (Cheddadi et al., 2001). Consequently, significant reductions in productivity are expected and, it is therefore important to adopt appropriate management techniques in order to maintain forage production under the more severe drought conditions.

In the warm and dry Mediterranean environments, arbuscular mycorrhizal (AM) symbiosis could play an important role in alleviating the effects of drought on crop yield. Arbuscular mycorrhizal fungi (AMF) symbiosis could significantly improve plant resistance to drought via increased dehydration-avoidance and increased tolerance (Ruiz-Lozano and Azcón, 2000). However, its efficacy should be linked to the plant AMF functional compatibility. The root colonization by the mycorrhiza increases active absorptive surface area and stimulates water uptake even in water stress conditions. The AMF symbiosis could increase the drought tolerance via the increased soil water movement to the plant roots (Ruiz-Lozano, 2003), and the ability of the mycorrhizal plants to mediate the osmotic stress. These osmotic regulations are related to the sugar level adjustments in the plant shoots (Wu and Xia, 2006). AMF plants postpone declines in water potential during drought stress (Porcel and Ruiz-Lozano, 2004). The ability of the fungus to enhance the water uptake and transport it in the plant, could explain these effects. What is more, the effects of AMF to the drought - plant relation also extend to the soil environment by promoting soil aggregation and thus improving the overall soil water conditions to the rhizosphere (Rillig et al., 2002).

Dactylis glomerata L. is a widespread perennial grass species, distributed throughout Eurasia including the Mediterranean basin (Lumaret, 1988). It is considered as one of the most important forage species due to its high productivity and nutritive value. Although its populations 
and varieties thrive in a multitude of environments and many of them have been reported as well adapted to drought stress conditions (García and Lindner, 1998; Stewart and Ellison, 2010), little information is available regarding the effects of AMF colonization on its growth characteristics.

The beneficial effect of mycorrhizal colonization on many field crops has been well documented. However, limited information is available concerning the selection of effective mycorrhizae and exploitation of their beneficial effects on enhancing the forage production of Dactylis glomerata in the Mediterranean region. The understanding of growth characteristics and dry matter production as affected by AMF colonization is important for the sustainable utilization of $D$. glomerata swards under the predicted future warmer and drier conditions. The general objective of this study was to test the effects of various AMF on growth characteristics and dry matter production of Dactylis glomerata in relation to different water availability.

\section{Materials and methods}

The experiment was conducted at the farm of the Democritus University of Thrace, in Orestiada, Northeastern Greece $\left(41^{\circ} 33^{\prime} \mathrm{N}, 26^{\circ} 31^{\prime} \mathrm{E}\right)$, at an altitude of $33 \mathrm{~m}$ above sea level. The climate of the area is characterized as subMediterranean. The mean annual precipitation is $515 \mathrm{~mm}$, and the mean annual temperature is $14.2^{\circ} \mathrm{C}$.

Seeds of the perennial grass species Dactylis glomerata L. collected from grasslands in the surrounding area during the summer of 2011, were sown into 40 plastic pots (10 lt volume) full of surface soil $(0-20 \mathrm{~cm})$ from the Democritus University farm mixed with sand, in March 2012. The soil is silty clay with $\mathrm{pH} 7.5$ (1:2 water), organic matter $20.5 \mathrm{~g} \mathrm{~kg}^{-1}$, electrical conductivity $0.04 \mathrm{~S} \mathrm{~m}^{-1}$, total $\mathrm{N} 1.11 \mathrm{~g} \mathrm{~kg}^{-1}, \mathrm{~N}^{-1} \mathrm{NO}_{3} 9 \mathrm{mg}$ $\mathrm{kg}^{-1}, \mathrm{P}$ (Olsen) $13.2 \mathrm{mg} \mathrm{kg}^{-1}$, and available K $178 \mathrm{mg} \mathrm{kg}$ (Koutroubas et al., 2012). The total seeding density was seven seeds per pot. Two weeks after the emergence of the seeds, some seedlings were removed from every pot in order to acquire a planting density of two seedlings per pot. The pots were then placed in an open area and subjected to a full irrigation treatment for a month prior to the onset of the experiment.

Two different irrigation treatments were applied once the experiment commenced: (1) up to full capacity and (2) $33 \%$ of full capacity. AMF application treatments were defined as: (1) control (no addition of AMF); (2) Glomus intraradices Schenck and Smith inoculation; (3) Glomus mosseae (Nicol and Gerd) Gerdemann and Trappe (Gm) inoculation; (4) mix of Glomus intraradices and Glomus mosseae inoculation. In the AMF inoculated pots, $8 \mathrm{ml}$ of $10 \% \mathrm{w} / \mathrm{v}$ water-inoculum solution $\left(25\right.$ spores $\left.\mathrm{g}^{-1}\right)$ was applied $3 \mathrm{~cm}$ below the depth of seeding in each pot before sowing. The pots were arranged in a completely randomized block (block in irrigation levels) with five replications. All pots were randomized within each irrigation treatment biweekly. Hand weeding was done when required.

The number of tillers per plant, the length of tillers from the base to the tip, the number of leaves per plant and the length of the leaf lamina between the ligule of the youngest fully expanded to the tip of the emerging leaf were measured twice a week, during the growing season (May-June).
Subsequently, Leaf Elongation Rate was calculated: Leaf Elongation Rate $(\mathrm{LER})=(\mathrm{L} 2-\mathrm{L} 1) / \mathrm{t}$, where $\mathrm{L} 1$ is the leaf length at the beginning and L2 is the leaf length at the end of a time ( $t$ ), (Lemaire and Agnusdei, 2000). The plants from all the pots were removed at late June 2012 and ovendried at $60{ }^{\circ} \mathrm{C}$ for $48 \mathrm{~h}$. Shoot and root samples were weighed in order to determine shoot dry weight (gr plant $\left.{ }^{-1}\right)$ and root dry weight (gr plant ${ }^{-1}$ ) and to calculate the $S / R$ ratio.

Root samples were cleared and stained and mycorrhizal colonization was evaluated according to Trouvelot $e t$ al. (1986). It expressed as percentage of mycorrhization (M\%) and percentage of arbuscules in the root system (A\%).

Data for the shoot dry weight, root dry weight, the $S / R$ ratio, the leaf growth rate, mycorrhizal colonization and the percentage of arbuscules in the root system were analyzed as completely randomized block design with two irrigation treatments and four AMF colonization treatments (Quinn and Keough, 2002) with five replications. Data for the number of tillers, the length of tillers and the number of leaves per plant were analyzed as completely randomized block design in time with two irrigation treatments and four AMF colonization treatments (Quinn and Keough, 2002). General linear models procedure (SPSS 18 for Windows) was used for ANOVA. The LSD at the 0.05 probability level was used to detect the differences among means (Steel and Torrie, 1980).

\section{Results and discussion}

Mycorrhizal colonization did not vary with water stress
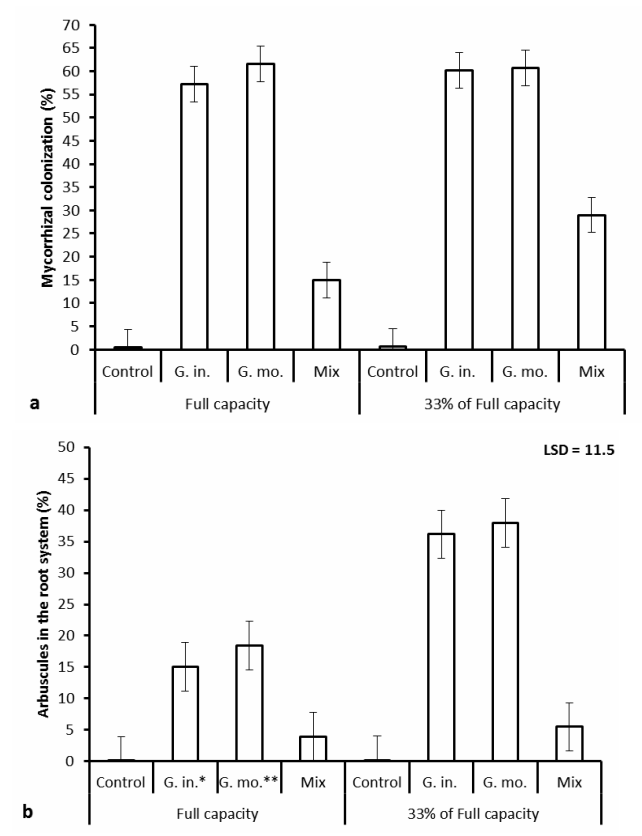

Fig. 1. (a) Percentage of mycorrhizal colonization (Mean \pm S.E.) and (b) percentage of arbuscules (Mean \pm S.E.) in Dactylis glomerata plants grown under well-watered conditions (up to full capacity) and drought stressed (33\% of full capacity)

* Glomus intraradices

** Glomus mosseae 
134

treatment (Fig. 1a). Similar results are common in studies involved potted plants (Auge, 2001). AMF development could be influenced not only by soil water content but also by differences in host and soil factors (Bethlenfalvay et al., 1988). Generally, the colonization of both the studied mycorrhizae species was satisfactory and superior to that of their mixture. Both water stress and mycorrhizae application affected significantly the percentage of arbuscules in the root system (Fig. 1b).

Under limited irrigation the percentage of arbuscules in the root system increased, while reduced arbuscules (\%) were found in plants inoculated with the mix of mycorrhizae species.

Water stress and mycorrhizae application affected significantly shoot dry weight, root dry weight, $S / R$ ratio and the number of leaves per plant of Dactylis glomerata
(Tab. 1). Additionally, significant differences for leaf growth rate and number of tillers per plant were recorded only between the irrigation treatments, while for tiller height only among the tested AMF colonization treatments. The dates of measurements affected significantly the number of leafs and the number of tillers, but did not affect the tillers' height. Significant interaction was observed between the irrigation and the mycorrhizae treatments only for root dry weight, $\mathrm{S} / \mathrm{R}$ ratio, the number of tillers and tillers' height (Tab. 1), indicating that the water stress effect was not consistent in the mycorrhizae. Moreover, the interaction of irrigation treatment and dates of measurements was significant for the number of leaves and the number of tillers.

The shoot dry weight (across mycorrhizae treatments) and the $S / R$ ratio of limited watered plants reduced

Tab. 1. Statistical significance of $\mathrm{F}$ ratios from the analysis of variance for dry weighs of shoot and root, on $\mathrm{S} / \mathrm{R}$ ratio and on growth parameters

\begin{tabular}{ccccccccc}
\hline $\begin{array}{c}\text { Source of } \\
\text { variation }\end{array}$ & df & A. $\mathrm{b}^{1}$ & $\mathrm{U}^{2}$ & $\mathrm{~A} / \mathrm{U}^{3}$ & LGR $^{4}$ & No Leafs & No Tillers & Tiller Height \\
\hline Water (W) & 1 & $\mathrm{p} \leq 0.05$ & $\mathrm{p} \leq 0.05$ & $\mathrm{p} \leq 0.05$ & $\mathrm{p} \leq 0.05$ & $\mathrm{p} \leq 0.05$ & $\mathrm{p} \leq 0.05$ & $\mathrm{NS}$ \\
Mycorrhiza (M) & 3 & $\mathrm{p} \leq 0.05$ & $\mathrm{p} \leq 0.05$ & $\mathrm{p} \leq 0.05$ & $\mathrm{NS}$ & $\mathrm{p} \leq 0.05$ & $\mathrm{NS}$ & $\mathrm{p} \leq 0.05$ \\
Date (D) & 5 & & & & & $\mathrm{p} \leq 0.05$ & $\mathrm{p} \leq 0.05$ & $\mathrm{NS}$ \\
WXM & 3 & $\mathrm{NS}$ & $\mathrm{p} \leq 0.05$ & $\mathrm{p} \leq 0.05$ & $\mathrm{NS}$ & $\mathrm{NS}$ & $\mathrm{p} \leq 0.05$ & $\mathrm{p} \leq 0.05$ \\
WXD & 5 & & & & & $\mathrm{p} \leq 0.05$ & $\mathrm{p} \leq 0.05$ & $\mathrm{NS}$ \\
MXD & 15 & & & & & $\mathrm{NS}$ & $\mathrm{NS}$ & $\mathrm{NS}$ \\
WXMXD & 15 & & & & & $\mathrm{NS}$ & $\mathrm{NS}$ & $\mathrm{NS}$ \\
\hline
\end{tabular}

F Test at $\mathrm{p} \leq 0.05$

${ }^{1}$ Aboveground biomass, ${ }^{2}$ Underground biomass, ${ }^{3}$ Aboveground/Underground, ${ }^{4}$ Leaf Growth Rate

Tab. 2. Effects of watering (across mycorrhiza application treatments) on dry weighs of shoot and root, on $\mathrm{S} / \mathrm{R}$ ratio and on growth parameters (Mean \pm S.E.) of Dactylis glomerata

\begin{tabular}{cccc}
\hline Treatment & Watered & Drought stressed & LSD $_{0.05}$ \\
\hline Shoot dry weight $(\mathrm{gr})$ & $1.22 \pm 0.03^{\mathrm{a}}$ & $0.91 \pm 0.03^{\mathrm{b}}$ & 0.09 \\
Root dry weight $(\mathrm{gr})$ & $2.68 \pm 0.24^{\mathrm{b}}$ & $4.56 \pm 0.25^{\mathrm{a}}$ & 0.71 \\
S/R & $0.65 \pm 0.03^{\mathrm{a}}$ & $0.24 \pm 0.03^{\mathrm{b}}$ & 0.09 \\
Number of tillers & $6.96 \pm 0.16^{\mathrm{a}}$ & $6.31 \pm 0.16^{\mathrm{b}}$ & 0.44 \\
Tiller height $(\mathrm{cm})$ & $17.41 \pm 0.16^{\mathrm{a}}$ & $17.44 \pm 0.16^{\mathrm{a}}$ & $\mathrm{N}$ \\
Number of leaves & $6.44 \pm 0.15^{\mathrm{a}}$ & $5.95 \pm 0.15^{\mathrm{b}}$ & 0,42 \\
Leaf growth rate $(\mathrm{cm} / \mathrm{d})$ & $0.18 \pm 0.01^{\mathrm{a}}$ & $0.14 \pm 0.01^{\mathrm{b}}$ & 0,03 \\
\hline
\end{tabular}

Means within each row followed by the same letter are not significantly different (LSD Test, $\mathrm{p} \leq 0.05$ ).
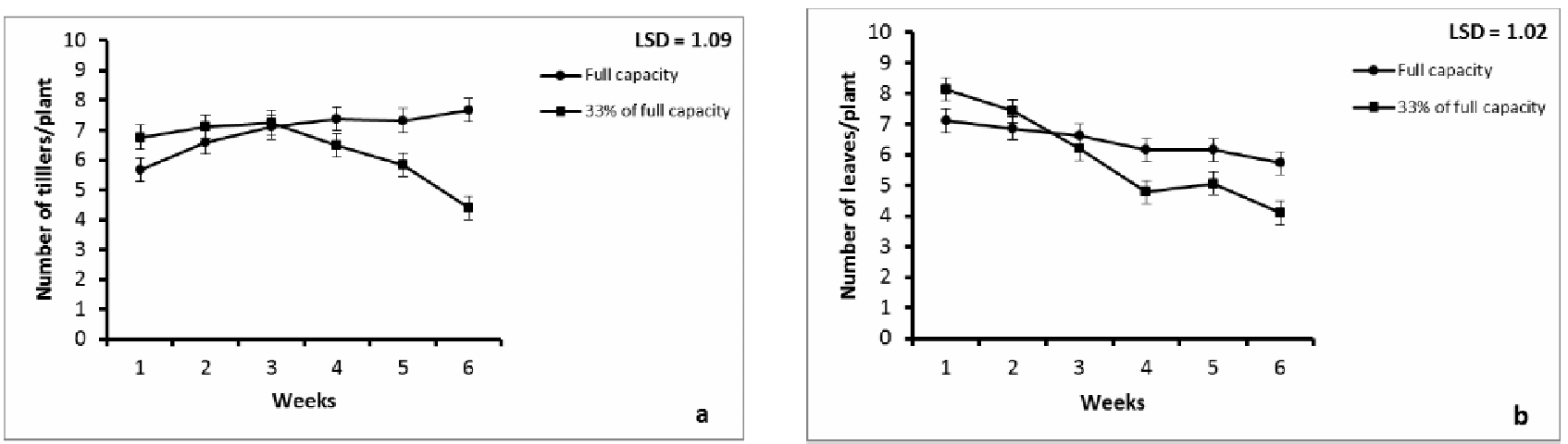

Fig. 2. Number of tillers (a) and number of leaves (b) of Dactylis glomerata for the two irrigation treatments (across AMF application treatments) during the experimental period 
approximately $25 \%$ and $63 \%$ respectively, while the root dry weight increased almost $70 \%$ (Tab. 2). Similarly, the number of leaves, number of tillers and leaf growth rate were significantly lower for limited watered plants compared to well watered ones, while the tiller height did not significantly differ between them (Tab. 2). The number of tillers and number of leaves under limited irrigation reduced significantly after the fourth and third week respectively (Fig. 2).

The results of the present study suggest that limited irrigation decreases significantly yield and yield components in Dactylis glomerata. It has to be noted that the decreased leaf growth rate recorded at plants grown under drought stress conditions has been described as a protection mechanism of grasses grown under drought conditions (Volaire et al., 2009; Wang and Bughrara, 2008). Drought stressed plants had significantly higher root dry weight. This result is associated with the fact that many grass species growing in drought conditions tend to increase their roots in order to increase their active absorptive surface area for water uptake. This response is a water restriction tolerance mechanism for the better survival of grasses under water deficit conditions (Lopez et al., 2013). These results confirm the fact that soil moisture constitutes a critical factor for plant growth and herbage production in the Mediterranean region (Etienne, 1996).

The AMF inoculated plants (across the irrigation treatments) had significant higher shoot dry weight compared to the non-inoculated plants, while there were no significant differences among the mycorrhizae application treatments (Tab. 3). Similarly, the AMF inoculated plants had higher tiller height and number of leaves in comparison to the non-inoculated plants, while the number of tillers and leaf growth rate did not significant differ between them (Tab. 3). Among the mycorrhizae treatments, the plants with Glomus intraradices had the highest tiller height and number of leaves although their tiller height did not differ significantly from these of Glomus mosseae and their number of leaves from these of their mix. On the contrary, the root dry weight of both Glomus intraradices and Glomus mosseae inoculated plants was the lowest although this of Glomus mosseae inoculated plants did not differ significantly from root dry weight of the mix and the non-inoculated plants. Additionally, the Glomus intraradices inoculated plants had the highest $S / R$ ratio, while the mix and noninoculated plants the lowest one. The opposite trend of the irrigation treatment main effect was observed for plants of the mix mycorrhizae species which had significantly higher root dry weight, lower number of tillers and tillers' height under well watered compared to limited watered conditions (Tab. 4).

Arbuscular mycorrhizal fungi (AMF) inoculation seems to improve Dactylis glomerata yield, due to the increase of shoot dry weight, $\mathrm{S} / \mathrm{R}$ ratio, tiller height and number of

Tab. 3. Effects of mycorrhiza colonization (across watering treatments) on dry weighs of shoot and root, on S/R ratio and on growth parameters (Mean \pm S.E.) of Dactylis glomerata

\begin{tabular}{cccccc}
\hline Treatment & Control & Glomus intraradices & Glomus mosseae & Mixed AM & LSD $_{0.05}$ \\
\hline Shoot dry weight $(\mathrm{gr})$ & $0.94 \pm 0.05^{\mathrm{b}}$ & $1.14 \pm 0.05^{\mathrm{a}}$ & $1.11 \pm 0.05^{\mathrm{a}}$ & $1.09 \pm 0.05^{\mathrm{a}}$ & 0.14 \\
Root dry weight $(\mathrm{gr})$ & $4.33 \pm 0.35^{\mathrm{a}}$ & $2.64 \pm 0.35^{\mathrm{b}}$ & $3.39 \pm 0.35^{\mathrm{ab}}$ & $4.14 \pm 0.37^{\mathrm{a}}$ & 1.00 \\
S/R & $0.38 \pm 0.05^{\mathrm{bc}}$ & $0.64 \pm 0.05^{\mathrm{a}}$ & $0.47 \pm 0.05^{\mathrm{b}}$ & $0.30 \pm 0.05^{\mathrm{c}}$ & 0.13 \\
Number of tillers & $6.36 \pm 0.23^{\mathrm{a}}$ & $6.92 \pm 0.24^{\mathrm{a}}$ & $6.61 \pm 0.23^{\mathrm{a}}$ & $6.65 \pm 0.24^{\mathrm{a}}$ & $\mathrm{NS}^{\mathrm{b}}$ \\
Tiller height $(\mathrm{cm})$ & $16.59 \pm 0.22^{\mathrm{c}}$ & $18.26 \pm 0.23^{\mathrm{a}}$ & $17.68 \pm 0.22^{\mathrm{ab}}$ & $17.17 \pm 0.23^{\mathrm{bc}}$ & 0.62 \\
Number of leaves & $5.49 \pm 0.21^{\mathrm{c}}$ & $6.81 \pm 0.23^{\mathrm{a}}$ & $6.06 \pm 0.21^{\mathrm{bc}}$ & $6.44 \pm 0.23^{\mathrm{ab}}$ & 0.59 \\
Leaf growth rate $(\mathrm{cm} / \mathrm{d})$ & $0.14 \pm 0.01^{\mathrm{a}}$ & $0.18 \pm 0.01^{\mathrm{a}}$ & $0.16 \pm 0.01^{\mathrm{a}}$ & $0.16 \pm 0.01^{\mathrm{a}}$ & $\mathrm{NS}$ \\
\hline
\end{tabular}

Means within each row followed by the same letter are not significantly different (LSD Test, $\mathrm{p} \leq 0.05$ ).

Tab. 4. Effects of watering and mycorrhiza colonization on dry weighs of shoot and root, on S/R ratio and on growth parameters (Mean \pm S.E.) of Dactylis glomerata

\begin{tabular}{|c|c|c|c|c|c|c|c|}
\hline Treatments & $\begin{array}{c}\text { Shoot dry } \\
\text { weight (gr) }\end{array}$ & $\begin{array}{c}\text { Root dry } \\
\text { weight (gr) }\end{array}$ & S/R & $\begin{array}{c}\text { Number of } \\
\text { tillers }\end{array}$ & $\begin{array}{l}\text { Tiller height } \\
(\mathrm{cm})\end{array}$ & $\begin{array}{c}\text { Number of } \\
\text { leaves }\end{array}$ & $\begin{array}{l}\text { Leaf growth } \\
\text { rate }(\mathrm{cm} / \mathrm{d})\end{array}$ \\
\hline \multicolumn{8}{|l|}{ Watered } \\
\hline Control & $1.12 \pm 0.07$ & $1.93 \pm 0.49 \mathrm{de}$ & $0.64 \pm 0.07^{b}$ & $7.71 \pm 0.32^{a}$ & $17.39 \pm 0.32^{b c}$ & $5.85 \pm 0.30$ & $0.16 \pm 0.02$ \\
\hline Glomus intraradices & $1.23 \pm 0.07$ & $1.26 \pm 0.49^{\mathrm{e}}$ & $1.01 \pm 0.07^{\mathrm{a}}$ & $7.78 \pm 0.35^{\mathrm{a}}$ & $18.37 \pm 0.35^{a}$ & $6.94 \pm 0.34$ & $0.20 \pm 0.02$ \\
\hline Glomus mosseae & $1.35 \pm 0.07$ & $1.94 \pm 0.49^{\mathrm{de}}$ & $0.73 \pm 0.07^{b}$ & $6.96 \pm 0.32^{\mathrm{ab}}$ & $17.34 \pm 0.32^{b c}$ & $6.68 \pm 0.30$ & $0.18 \pm 0.02$ \\
\hline Mixed AM & $1.19 \pm 0.07$ & $5.61 \pm 0.49^{a b}$ & $0.22 \pm 0.07^{\mathrm{cd}}$ & $5.99 \pm 0.32^{c}$ & $16.63 \pm 0.32^{\mathrm{cd}}$ & $6.30 \pm 0.30$ & $0.17 \pm 0.02$ \\
\hline \multicolumn{8}{|l|}{ Drought stressed } \\
\hline Control & $0.76 \pm 0.07$ & $6.74 \pm 0.49^{a}$ & $0.11 \pm 0.07^{\mathrm{d}}$ & $5.62 \pm 0.32^{c}$ & $15.78 \pm 0.32^{\mathrm{d}}$ & $5.12 \pm 0.30$ & $0.12 \pm 0.02$ \\
\hline Glomus intraradices & $1.05 \pm 0.07$ & $4.02 \pm 0.49^{\mathrm{cd}}$ & $0.27 \pm 0.07^{\mathrm{cd}}$ & $6.05 \pm 0.32^{c}$ & $18.16 \pm 0.32^{\mathrm{a}}$ & $6.67 \pm 0.30$ & $0.16 \pm 0.02$ \\
\hline Glomus mosseae & $0.86 \pm 0.07$ & $4.82 \pm 0.49^{b c}$ & $0.22 \pm 0.07^{\mathrm{cd}}$ & $6.26 \pm 0.32^{b c}$ & $18.03 \pm 0.32^{\mathrm{ab}}$ & $5.44 \pm 0.30$ & $0.15 \pm 0.02$ \\
\hline Mixed AM & $0.98 \pm 0.07$ & $2.66 \pm 0.55^{d}$ & $0.38 \pm 0.07^{c}$ & $7.31 \pm 0.35^{a}$ & $17.80 \pm 0.35^{\mathrm{ab}}$ & $6.57 \pm 0.34$ & $0.15 \pm 0.02$ \\
\hline $\mathrm{LSD}_{0.05}$ & NS & 1.41 & 0.19 & 0.89 & 0.88 & NS & NS \\
\hline
\end{tabular}

Means within each column followed by the same letter are not significantly different (LSD Test, $\mathrm{p} \leq 0.05$ ). 
136

leaves under up to full and limited irrigation. This could be associated with the higher accumulation of phosphorus, nitrogen and potassium from the soil (Erman et al., 2011; Jacobsen, 1994; Pearson and Jacobsen, 1993).

In contrast, under drought stress conditions all AMF plants had lower root dry weights than control plants. This result is in agreement with $\mathrm{Di}$ and Allen (1991) for Agropyron cultivars and Cavagnaro et al. (2008) for Solanum lycopersicum who also found that AMF colonization of plants decreased root biomass. It seems that the AMF inoculated plants cope with water deficit by other mechanisms and not by increasing the root biomass at the expense of shoot biomass. For instance, the AMF inoculated plants of Agropyron cultivars performed better under water stress due to their higher water use efficiency compared to non-inoculated ones (Di and Allen, 1991). According to Ruiz-Lozano et al. (1995), there is a differentiated effect on plant adaptation to drought among the AMF species. The seven fungal species of genus Glomus they studied had the particular ability to alter the physiological parameters that enhance the adaptation of Lactuca sativa L. cv. Romana to low soil water content. Additionally, the low root dry weight can be associated with the AMF symbiosis, which improved significantly the resistance of the inoculated plants to drought by reducing the need of an increase to the roots.

Among the studied mycorrhizae species, Glomus intraradices performed better than Glomus mosseae and their mixture as it increased $S / R$ ratio, tiller height and number of leaves. In contrast to our results, Moradi and Salimi (2013) reported that Glomus mosseae was more effective for the growth parameters of Poa sp. This confirms that AMF inoculation has positive effects on various plants, but there are variations in response of the varieties, cultivars or species to various AMF species (Long et al., 2010; Naher et al., 2013; Tufenkci et al., 2012; Wang et al., 2008,). The mix of these mycorrhiza species although it increased the growth parameters of Dactylis glomerata in comparison to the control, it was inferior to the other AMF application treatments. Moreover, the mix reduces drastically the root system of the plants under limited irrigation, which could detrimentally affect the plants growth under prolonged drought and the sward persistence. This is probably has to do with the interaction between the two mycorrhiza species that reduces their positive effect to plants. The variation upon the growth response is not unusual, with mycorrhizal growth response varying from positive to neutral or negative. These responses are influenced by the symbiotic partners, the genotypes, the developmental stages and the environmental conditions (Facelli et al., 2010; Klironomos, 2003; Smith and Smith, 2011). In particular, the soil conditions could determine how well the non mycorrhizal plants grow in relation to mycorrhizal plants. Negative response also correlates with the higher symbiotic cost in relation to the photosynthetic supply (Jacobsen, 1999). However, the negative growth response as reported here, the reduced number of tillers, may be related to a hormonal response to AMF. Strigolactones, a newly described plant hormone are connected with the number of the tillers in plants (Foo and Reid, 2013). AMF and strigolactones interactions could result to a reduced number of tillers.
When plant roots were inoculated by two AMF species, increased the levels of the stigolactones in the shoot leading to tiller reduction.

\section{Conclusions}

In conclusion, this study provided evidence that AMF have the potential to be beneficial on growth characteristics and dry matter production of Dactylis glomerata grown under different water availability conditions. The beneficial activity of AMF is most likely to be favored under drought stress. Therefore, further studies on Dactylis glomerataAMF symbiosis in the field are needed in order this symbiosis to be tested under plant competition and grazing conditions. The increased number of leaves found in the inoculated plants is an indicator of ameliorated nutritive value (Parissi et al., 2007) but the effects of AMF inoculation on the forage quality of Dactylis glomerata also need to be tested.

\section{References}

Augé RM (2001). Water relations, drought and vesiculararbuscular mycorrhizal symbiosis. Mycorrhiza 11:3-42.

Bethlenfalvay GJ, Brown MS, Ames RN, Thomas RS (1988). Effects of drought on host and endophyte development in mycorrhizal soybeans in relation to water use and phosphate uptake. Physiol Plant 72:565-571.

Bates BC, Kundzewicz ZW, Wu S, Palutikof JP (2008). Climate Change and Water. Technical Paper, IPCC Secretariat, Geneva, p. 210.

Cavagnaro TR, Langley AJ, Jackson LE, Smukler SM, Koch GW (2008). Growth, nutrition, and soil respiration of a mycorrhiza-defective tomato mutant and its mycorrhizal wild type progenitor. Funct Plant Biol 35:228-235.

Cheddadi R, Guiot J, Jolly D (2001). The Mediterranean vegetation: What if the atmospheric $\mathrm{CO}_{2}$ increased? Landscape Ecol 16:667-675.

Di JJ, Allen EB (1991). Physiological responses of six wheatgrass cultivars to mycorrhizae. J Range Manage 44:336-341.

Etienne M (ed.) (1996). Research on temperate and tropical silvopastoral systems: a review, pp: 5-19. In: Western European Silvopastoral Systems. INRA Editions, Paris, France.

Erman M, Demirb S, Ocakc E, Tüfenkci S, Oguz F, Akköprü A (2011). Effects of Rhizobium, arbuscular mycorrhiza and whey applications on some properties in chickpea (Cicer arietinum $\mathrm{L}$.) under irrigated and rainfed conditions 1 - Yield, yield components, nodulation and AMF colonization. Field Crop Res 122:14-24.

Facelli E, Smith SE, Facelli JM, Christophersen HM, Smith FA (2010). Underground friends or enemies: model plants help to unravel direct and indirect effects of arbuscular mycorrhizal fungi on plant competition. New Phytol 185:1050-1061.

Foo E, Reid JB (2013). Strigolactones: New Physiological Roles for an Ancient Signal. Plant Growth Regul 32:429-442.

Garcia A. Lindner R (1998). Dactylis glomerata genetic resources: 
Allozyme frequencies and performance of two subspecies on an acid sandy loam with summer drought. Euphytica 120: 255-264.

Jacobsen I (1994). Research approaches to study the functioning of vesicular arbuscular mycorrhizas in the field. Plant Soil 159:141-142.

Jakobsen I (1999). Transport of phosphorus and carbon in arbuscular mycorrhizas, p. 309-332. In: Varma A, Hock B (Eds.). Mycorrhiza: Structure, Function, Molecular Biology and Biotechnology, Springer, Berlin, Germany.

Klironomos JN (2003). Variation in plant response to native and exotic arbuscular mycorrhizal fungi. Ecology 84:2292-2301.

Koutroubas SD, Fotiadis S, Damalas CA (2012). Biomass and nitrogen accumulation and translocation in spelt (Triticum spelta) grown in a Mediterranean area. Field Crop Res 127:18.

Lemaire G, Agnusdei M (2000). Leaf tissue turnover and efficiency of herbage utilization, pp. 265-287. In: Lemaire G, Hodgson J, de Moraes A, Nabinger C, de F Carvalho PC (Eds.). Grassland ecophysiology and grazing ecology. CAB International, Wallingford, UK.

Long LK, Yao Q, Huang YH, Yang RH, Guo J, Zhu HH (2010). Effects of arbuscular mycorrhizal fungi on zinnia and the different colonization between Gigaspora and Glomus. World J Microbiol Biotechnol 26:1527-1531.

López IF, Kemp PD, Dörner J, Descalzi CA, Balocchi OA, García $S$ (2013). Competitive strategies and growth of neighbouring Bromus valdivianus Phil. and Lolium perenne L. plants under water restriction. J Agron Crop Sci 199:449-459.

Lumaret R (1988). Cytology, genetics and evolution in the genus Dactylis. Crit Rev Plant Sci 7:55-91.

Moradi S, Salimi S (2013). Effects of arbuscular mycorrhizal fungi on root morphological properties of Poa in drought stress conditions. Int J Agri Crop Sci 5:591-595.

Naher UA, Othman R, Panhwar QA (2013). Beneficial effects of mycorrhizal association for crop production in the tropics - a review. Int J Agr Biol 15:1021-1028.

Parissi ZM, Abraham EM, Karameri E, Kexagia E, Karatassiou M (2007). Comparable study of the nutritive value in Greek populations of Dactylis glomerata L. growing in contrasting environments in association to maturity. Grassland Sci Eur 12:371-374.

Pearson JN, Jakobsen I (1993). Symbiotic exchange of carbon and phosphorus between cucumber and three arbuscular mycorrhizal fungi. New Phytol 124:481-488.

Porcel R, Barea JM, Ruiz-Lozano JM (2003). Antioxidant activities in mycorrhizal soybean plants under drought stress and their possible relationship to the process of nodule senescence. New Phytol 157:135-143.
Quinn GP, Keough MJ (2002). Experimental design and data analysis for biologists. Cambridge University Press, Cambridge, UK.

Rillig MC, Treseder KK, Allen MF (2002). Mycorrhizal fungi and global change, pp. 135-160. In: van der Heijden MGA, Sanders IR (Eds.). Mycorrhizal Ecology, Ecological Studies Series 157. Springer, Berlin, Germany.

Ruiz-Lozano JM (2003). Arbuscular mycorrhizal symbiosis and alliviation of osmotic stress. New perspectives for molecular studies. Mycorrhiza, 13: 309-317.

Ruiz-Lozano JM, Azcon R (2000). Symbiotic efficiency and infectivity of an autochthonous arbuscular mycorrhizal Glomus sp from saline soils and Glomus deserticola under salinity. Mycorrhiza 10:137-143.

Ruiz-Lozano JM, Azcón R, Gómez M (1995). Effects of arbuscular-mycorrhizal Glomus species on drought tolerance: physiological and nutritional plant responses. Appl Environ Microbiol 61:456-460.

Smith SE, Smith FA (2011). Roles of arbuscular mycorrhizas in plant nutrition and growth: new paradigms from cellular to ecosystem scales. Annu Rev Plant Biol 62:227-250.

Steel RGD, Torrie JH (1980). Principles and procedures of statistics. 2nd edn. McGraw-Hill, New York, USA.

Stewart AV, Ellison NW (2010). Dactylis, pp 73-87. In: Kole C (Ed.). Wild crop relatives: genomic and breeding resources, millets and grasses. Springer-Verlag, Berlin, Germany.

Trouvelot A, Kough JL, Gianinazzi-Pearson V (1986). Mesure du taux de mycorhization VA d'un système radiculaire. Recherche de méthodes d'estimation ayant une signification fonctionnelle, pp 217-221. In: Gianinazzi-Pearson V, Gianinazzi S (Eds.). Physiological and genetical aspects of Mycorrhizae. INRA Press, Paris, France.

Tufenkci S, Demir S, Şensoy S, Ünsal S, Demirer E, Erdinc C, Bicer S, Ekincial A, Kincialp A (2012). The effects of arbuscular mycorrhizal fungi on the seedling growth of four hybrid cucumber (Cucumis sativus L.) cultivars. Turk J Agric For 36:317-327.

Volaire F, Norton M, Lelievre F (2009). Summer drought survival strategies and sustainability of perennial temperate forage grasses in Mediterranean areas. Crop Sci 49:2386-2392.

Wang JP, Bughrara SS (2008). Morpho-physiological responses of several fescue grasses to drought stress. HortScience 43:776783.

Wang C, Li X, Zhou J, Wang G, Dong Y (2008). Effects of arbuscular mycorrhizal fungi on growth and yield of cucumber plants. Commun Soil Sci Plant Anal 39:499-509.

Wu QS, Xia RX (2006). Arbuscular mycorrhizal fungi influence growth, osmotic adjustment and photosynthesis of citrus under well-watered and water stress conditions. J Plant Physiol 163:417-425. 